\title{
Radioimmunoassay for Luteinizing Hormone in Human Plasma or Serum: Physiological Studies*
}

\author{
W. D. Odell, † G. T. Ross, ANd P. L. Rayford \\ (From the Endocrinology and Metabolism Branch, National Institute of Child Health and \\ Human Development, National Institutes of Health, Bethesda, Md.)
}

\begin{abstract}
Summary. It is not practical to quantitate gonadotropin in the blood of normal men and women by utilizing bioassays. We have developed a method for sensitive, precise, and specific radioimmunoassay of luteinizing hormone $(\mathrm{LH})$ in human serum or plasma. Antisera were developed against human chorionic gonadotropin, and one of these was selected for extensive cross-reaction with human LH. Highly purified LH was radioiodinated by the method of Greenwood, Hunter, and Glover. Separation of antibody-bound from free LH- ${ }^{131} \mathrm{I}$ was accomplished by a double antibody technique. Dose-response curves for the purified $\mathrm{LH}$, an impure urinary $\mathrm{LH}$ preparation, pituitary powder, and $\mathrm{LH}$ in plasma were all identical. Immunoassay and bioassay of impure urinary and pituitary gonadotropin preparations in terms of a common standard resulted in an index of discrimination of close to unity. LH levels in plasma from 32 adult men and 30 women outside the midcycle ranged from 0.6 to $3.2 \mathrm{~m} \mu \mathrm{g}$ per $\mathrm{ml}$ ( $1 \mathrm{~m} \mu \mathrm{g}$ of our laboratory LH standard is equivalent to $8 \mathrm{mU}$ of the Second International Reference Preparation of Human Menopausal Gonadotropin). Levels were remarkably constant in men from day to day and in women except at midcycle, when a sharp peak occurred lasting less than 24 hours. In all women studied who had a midcycle $\mathrm{LH}$ peak, mean plasma LH levels during the follicular phase of the menstrual cycle were higher than mean values obtained during the luteal phase. Prepubertal children had detectable plasma $\mathrm{LH}$, and mean values were only slightly less than in adults. Plasma from castrate men or women or postmenopausal women contained 4.5 to $10.5 \mathrm{~m} \mu \mathrm{g}$ per $\mathrm{ml}$. Clomiphene treatment of four men resulted in a doubling of plasma $\mathrm{LH}$ in 5 days.
\end{abstract}

\section{Introduction}

Wide, Roos, and Gemzell (1), using an immunoassay based on hemagglutination inhibition, first reported that human luteinizing hormone (HLH) cross-reacts with human chorionic gonadotropin (HCG) for binding to antibodies directed against HCG. In 1964 Paul and Odell (2) first developed a radioimmunoassay for HCG. Later we (3) developed a radioimmunoassay for

* Submitted for publication July 7, 1966; accepted October 27, 1966.

$\dagger$ Address requests for reprints to Dr. W. D. Odell, Dept. of Medicine, School of Medicine, University of California at Los Angeles, Harbor General Hospital Campus, Torrance, Calif. 90509.
HLH by taking advantage of the cross-reaction between HLH and HCG and the availability of a highly purified preparation of $\mathrm{HLH}$ suitable for radioiodination.

In 1965 Midgley and Ram (4) published an abstract of methods of radioimmunoassay for $\mathrm{HLH}$, and subsequently Midgley (5) and Franchimont (6) published reports of methods for radioimmunoassay for HLH. We wish to report details of our methodology and some results of physiological studies.

\section{Methods}

Preparation of antisera to $H L H$ (anti-HLH). All immunizations were performed by dissolving the antigen 
in saline and emulsifying this solution with an equal volume of complete Freund's adjuvant. ${ }^{1}$ Three $\mathrm{ml}$ of this mixture was given subcutaneously in two sites to each white New Zealand rabbit. Three such injections were administered 10 days apart. Animals were bled periodically by cardiac puncture starting 10 days after the last injection. Two gonadotropin preparations were used to prepare the antisera: 1) a preparation from urine of pregnant women ${ }^{2}(3,000$ IU was administered in each injection; antisera from 12 animals were studied), and 2) a preparation from urine of castrate men ${ }^{3}$ (12.5 mg was administered at each injection, and antisera from six animals were studied). All antisera were screened for titer and ability to bind a tracer amount of human luteinizing hormone labeled with ${ }^{131} \mathrm{I}\left(\mathrm{LH}-{ }^{131} \mathrm{I}\right)$ by incubating tenfold dilutions of the antisera with $0.05 \mathrm{~m} \mu \mathrm{g}$ of $\mathrm{LH}^{131} \mathrm{I}$. Antisera that bound more than $70 \%$ of this antigen at greater than $1: 10,000$ final dilution were further screened by running abbreviated dose-response curves of unlabeled $\mathrm{HLH}$ in the radioimmunoassay system. An antiserum directed against HCG was finally selected to develop the assay described.

Sheep antirabbit antisera were prepared by dissolving $100 \mathrm{mg}$ of rabbit $\gamma$-globulin 4 in $5 \mathrm{ml}$ of $0.9 \% \mathrm{NaCl}$ and mixing with $5 \mathrm{ml}$ of complete Freund's adjuvant. Ten $\mathrm{ml}$ of this mixture was injected subcutaneously into a sheep on the same schedule as described for rabbits. Two sheep were immunized and periodic bleeding was performed starting 10 days after the last injection. Every batch of antiserum was titered for ability to precipitate the antibody-bound $\mathrm{HLH}^{-131} \mathrm{I}$ mixture described later. An "excess" (usually $150 \mu \mathrm{l}$ ) was used as the second antibody for assay purposes.

Radioiodinated human luteinizing hormone. One $\mathrm{mg}$ of highly purified $\mathrm{HLH}$ was utilized in the development of this assay. This particular batch of $\mathrm{HLH}$ had not been bioassayed because insufficient material was available, but with similar methodology $\mathrm{HLH}$ preparations containing 6,400 IU per $\mathrm{mg}^{5}$ had been previously prepared (7). The HLH was dissolved in phosphate saline buffer ( $0.01 \mathrm{M}$ phosphate, $0.15 \mathrm{M} \mathrm{NaCl}, \mathrm{pH} 7.8)$ in concentrations of $0.1 \mathrm{mg}$ per $\mathrm{ml}$ and frozen in aliquots of $0.2 \mathrm{ml}$ for each assay. One or $2 \mu \mathrm{g}$ of this material was radioiodinated to specific activities of 200 to $500 \mu \mathrm{c}$ per $\mu \mathrm{g}$ by the method of Greenwood, Hunter, and Glover (8). $\mathrm{LH}^{-131} \mathrm{I}$ was separated from inorganic ${ }^{131} \mathrm{I}$ by passing through a G75 Sephadex column $(1.0 \times 15 \mathrm{~cm})$. The trailing edge of the earliest peak was used in the assay. LH- ${ }^{131}$ I was always utilized within 24 to 48 hours of preparation.

Performance of assay. The following buffer was used for all dilutions: $0.01 \mathrm{M}$ phosphate, $0.15 \mathrm{M} \mathrm{NaCl}, 0.1 \%$

1 Difco Laboratories, Detroit, Mich.

2 APL, Ayerst, New York, N. Y.

${ }^{3}$ HPGUE, National Institutes of Health study section.

4 Hyland Laboratories, Los Angeles, Calif.

${ }^{5}$ In terms of the Second International Reference Preparation of Human Menopausal Gonadotropin (2nd IRP HMG). sodium azide, $2.5 \%$ normal rabbit serum, $\mathrm{pH} 7.8$. All reagents were added to $1.0-\times 7.5-\mathrm{cm}$ tubes in the following order: 1) buffer to make a total volume of $1.0 \mathrm{ml}$, 2) $100 \mu \mathrm{l}$ of $0.1 \mathrm{M}$ EDTA, $\mathrm{pH} 7.6,3) 1.0$ to $300 \mu \mathrm{l}$ of plasma to be assayed (or of "standard" hormone), 4) 100 $\mu \mathrm{l}$ containing 0.05 to $0.15 \mathrm{~m} \mu \mathrm{g}$ of $\mathrm{HLH}^{131} \mathrm{I}$, and 5) 100 $\mu 1$ of antisera suitably diluted, usually $1: 30,000$ (final dilution, $1: 300,000)$.

Complete standard dose-response curves were run in all assays, and for this purpose known amounts of HLH were added instead of the plasma. All tubes were incubated for 5 days at $4^{\circ} \mathrm{C}$, at which time $150 \mu \mathrm{l}$ of the second antibody was added to each tube and the mixture incubated 24 hours longer at $4^{\circ} \mathrm{C}$ to achieve separation of antibody-bound from free $\mathrm{HLH}^{131} \mathrm{I}$, according to the method of Feinberg (9) as modified by Morgan, Sorenson, and Lazarow (10). Tubes were then centrifuged at $500 \mathrm{~g}$ and the supernatant was removed by suction. $\mathrm{Ra}-$ dioactivity was quantitated in an automatic gamma spectrometer, ${ }^{6}$ and all results were expressed as per cent of counts precipitated. Zero per cent was defined as no HLH- ${ }^{131} \mathrm{I}$ bound to antibody. Two to $5 \%$ of $\mathrm{HLH}^{131} \mathrm{I}$ was trapped in the precipitate nonspecifically, the value of these counts being obtained by quantitating precipitated counts in tubes containing no antibody. These counts could be removed by washing the precipitate, but this did not contribute significantly to precision of the assay, and this step was therefore omitted. The counter was then set so that these counts were automatically subtracted (as background). One hundred per cent was defined as the number of counts precipitated in tubes containing $\mathrm{HLH}_{-}{ }^{131} \mathrm{I}$ and antibody, but no unknown or standard LH. All tubes were counted for the time required for the " $100 \%$ tubes" to register 10,000 counts. Thus any tubes with unlabeled HLH present had HLH- ${ }^{131}$ I "displaced" from antibody, and the result was less than 10,000 counts precipitated. In this manner all results were expressed in relation to 10,000 counts and by shifting the decimal two places to the left were expressed as per cent. This procedure greatly simplified data processing.

Bioassay. Several samples were simultaneously bioassayed and immunoassayed in terms of the same human standard. Bioassays for $\mathrm{HLH}$ were done by means of the ventral prostate weight in hypophysectomized immature male rats (11). It is important to note that a human LH standard is required for the purposes of radioimmunoassay because $\mathrm{LH}$ of other species reacts poorly or not at all in the assay. Pergonal $1958^{7}$ was adopted as our laboratory standard for both bioassays and immunoassays. After repeated potency estimates in the radioimmunoassay $1 \mu \mathrm{g}$ of this laboratory standard was defined as equivalent to $2 \mathrm{~m} \mu \mathrm{g}$ of purified $\mathrm{HLH}$ and as equivalent to $0.016 \mathrm{IU}^{8}$ of $\mathrm{LH}$.

6 Picker X-Ray Corp., White Plains, N. Y.

7 Purchased from Instituto Farmacologico, Serono, Rome, Italy.

${ }^{8}$ In terms of international units of the 2nd IRP HMG. 


\section{Results}

Ninety-five per cent or more of the $\mathrm{HLH}^{-131} \mathrm{I}$ was precipitable in the presence of excess antiHLH. Figure 1 demonstrates a semilogarithmic dose-response curve for the purified HLH in the radioimmunoassay. The minimal amount detectable was $0.15 \mathrm{~m} \mu \mathrm{g}$ per $\mathrm{ml}(1.2 \mathrm{mU})$ of plasma when $300 \mu 1$ was assayed in each milliliter of reaction mixture. Also shown in Figure 1 on the same semilogarithmic scale is a dose-response curve for our laboratory standard (Pergonal). Note that this relatively impure gonadotropin preparation containing both follicle-stimulating hormone (HFSH) and HLH gives the same doseresponse curve as the purified $\mathrm{HLH}$ with the exception that 504 times as much is required to give the same response. In addition, a dose-response curve for acetone-dried human pituitary powder is shown. This material also gave a dose-response curve similar in shape to that of the purified HLH, but 1,000 times as much material was required for the same response. Figure 2 depicts dose-response curves for highly purified $\mathrm{HLH}$ and for plasma from a postmenopausal woman. Note the identical shapes of these dose-response curves.

Partially purified and highly purified prepara-

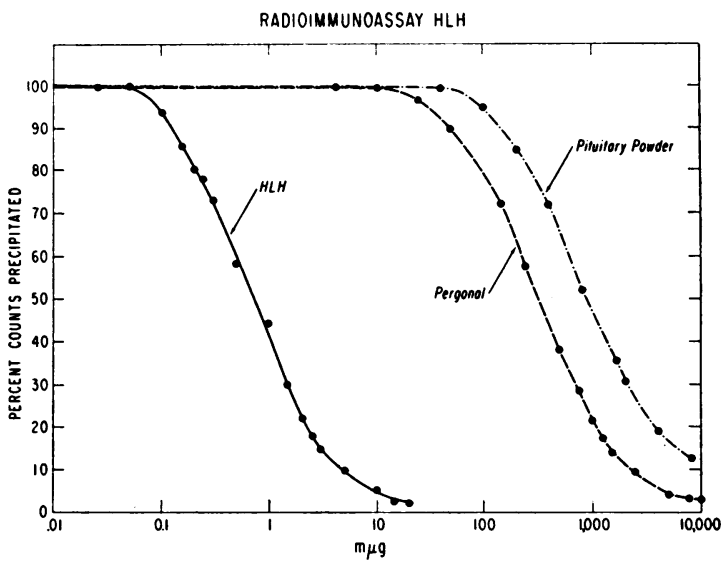

Fig. 1. Semilogarithmic plot of Dose-Response CURVES FOR HIGHLY PURIFIED HUMAN LUTEINIZING HORMONE (HLH), AN IMPURE URINARY PREPARATION (PERGONAL) CONTAINING BOTH FOLLICLE-STIMULATING HORMONE AND HLH, AND ACETONE-DRIED HUMAN PITUITARY POWDER. Five hundred times as much Pergonal and 1,000 times as much pituitary powder were required to give the same response. One $\mathrm{m} \mu \mathrm{g}$ is equivalent to $8 \mathrm{mU}$ of the Second International Reference Preparation of Human Menopausal Gonadotropin.

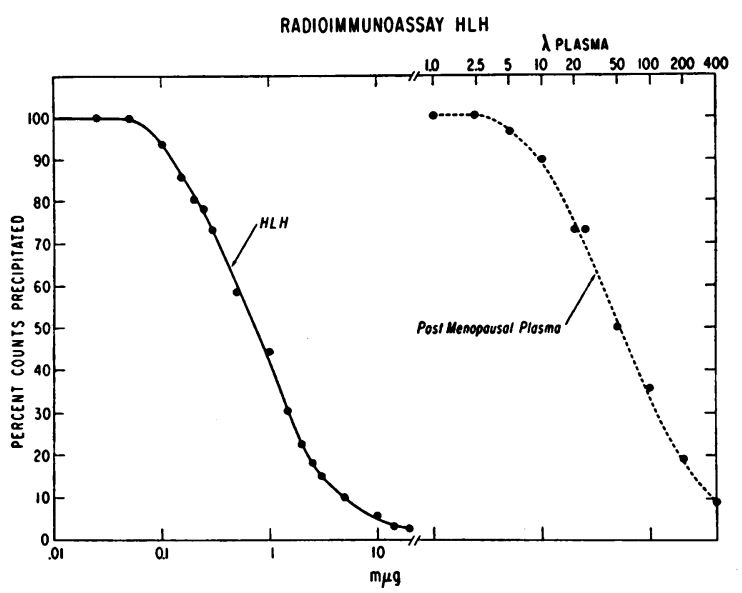

Fig. 2. Semilogarithmic Plot of DOSE-RESPONSE CURVES FOR HIGHLY PURIFIED HLH AND FOR THE HLH CONTENT OF PLASMA FROM POSTMENOPAUSAL WOMEN. The two points at $20 \mu 1$ are duplicate determinations.

tions from a number of sources have been assayed by this technique to assist in evaluation of specificity. Highly purified $\mathrm{HFSH}$, which initially assayed biologically at $100 \mathrm{IU}$ per $\mathrm{mg},{ }^{9}$ gave a dose-response curve identical to that of the HLH except that 100 times as much material (by weight) was required to give the same response, a phenomenon probably explained by a $1 \%$ contamination of the HFSH with HLH. Human thyrotropin ( $\mathrm{HTSH})$, which initially assayed at 20 $\mathrm{U}$ per $\mathrm{mg}$, also gave a dose-response curve identical to the HLH, but 20 times as much was required for the same response, a phenomenon probably explained by $5 \%$ contamination of the HTSH with HLH. The values for per cent contamination are similar to those obtained for both HTSH (12) and HFSH (13) by bioassay. The dose-response curve for human chorionic gonadotropin is also identical to HLH. As little as 0.002 $\mathrm{IU}^{10}$ may be detected. This is 50 times more sensitive than the mouse uterine weight assay (14). It is interesting that monkey chorionic gonadotropin shows minimal cross-reaction in this assay for $\mathrm{HLH}$, as much as $100 \mathrm{IU}$ giving the same response as $0.01 \mathrm{IU}$ of HCG. The differences in monkey and human chorionic gonadotropin will be presented in detail in a separate publication.

${ }^{9}$ Obtained through the kind generosity of Dr. Leo Reichert, Dept. of Biochemistry, Emory University, Atlanta, Ga.

10 The international unit of HCG is different from the international unit of the 2nd IRP HMG. 
TABLE I

Comparison of immunological and biological activity of human luteinizing hormone

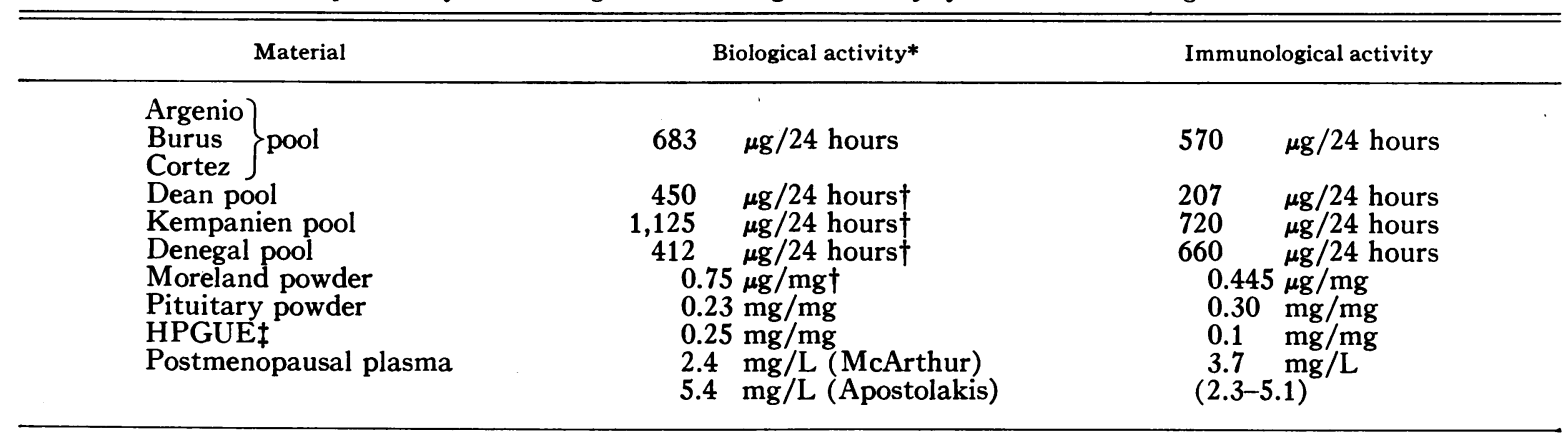

* In terms of Pergonal 1958.

† One on 3 assay design.

$\ddagger$ National Institutes of Health study section.

Several impure gonadotropin preparations (containing both $\mathrm{LH}$ and $\mathrm{FSH}$ ) were simultaneously assayed in the radioimmunoassay and in the prostate weight assay in terms of a common standard. Results are presented in Table I. For several samples only enough LH was present to permit a 1 on 2 bioassay design. The index of discrimination was close to unity in all cases, and in all cases the $95 \%$ confidence limits of the potency estimate by bioassay included the potency estimate by immunoassay.

Plasma from a number of sources has been examined for $\mathrm{HLH}$ content, and a scattergram of some of these data is presented in Figure 3. Plasma from eugonadal men and women except at midcycle contained an average of $1.8 \mathrm{~m} \mu \mathrm{g}$ per $\mathrm{ml}$ (range from 0.8 to 3.2). In men plasma values for HLH appeared fairly constant. Samples from four men under normal activity were obtained every 6 hours for 4 days and for two of these same men at times when 24-hour bed rest was maintained. No diurnal variation of $\mathrm{HLH}$ has been observed under any of these conditions. Plasma from children of both sexes between the ages of 8 and 12 years contained an average of 1.6 $\mathrm{m} \mu \mathrm{g}$ per $\mathrm{ml}$ ( 0.6 to 2$)$, and plasma from children 1 to 8 years of age contained an average of 1.0 $\mathrm{m} \mu \mathrm{g}$ per $\mathrm{ml}(0.6$ to 1.6$)$. The differences among all four of these groups are not statistically significant. The presence of gonadotropin in plasma from prepubertal children is discussed in more detail later.

Plasma from postmenopausal women and castrated men or women contained from 6 to $12 \mathrm{~m} \mu \mathrm{g}$ per $\mathrm{ml}$. There was no overlap in $\mathrm{LH}$ values from eugonadal men and women outside the midcycle. A single LH determination serves to differentiate primary from secondary gonadal failure in all cases we have yet seen.

Figure 4 depicts the plasma LH levels determined daily in a eugonadal woman throughout the menstrual cycle. Note that blood levels were

$$
\underset{m \mu g / m l}{H L H}
$$

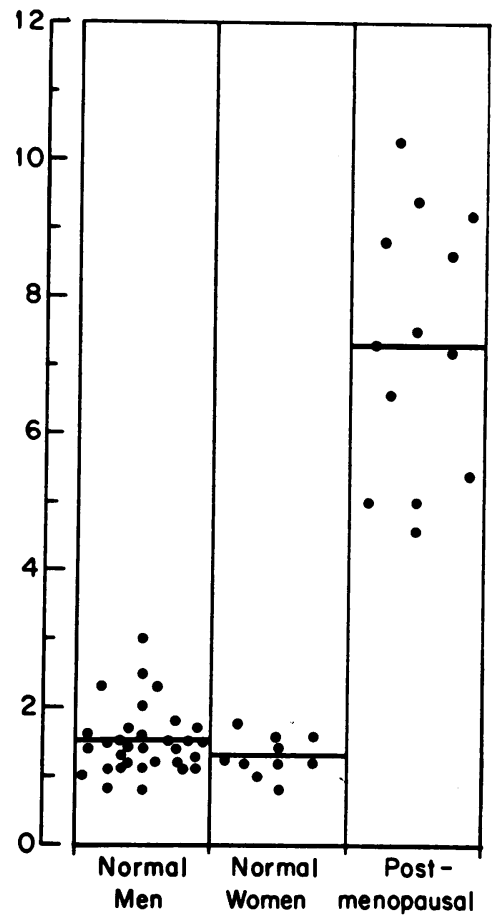

Fig. 3. Scattergram of HLH values in plasma FROM EUGONADAL MEN AND WOMEN AND FROM POSTMENOPAUSAL WOMEN. 


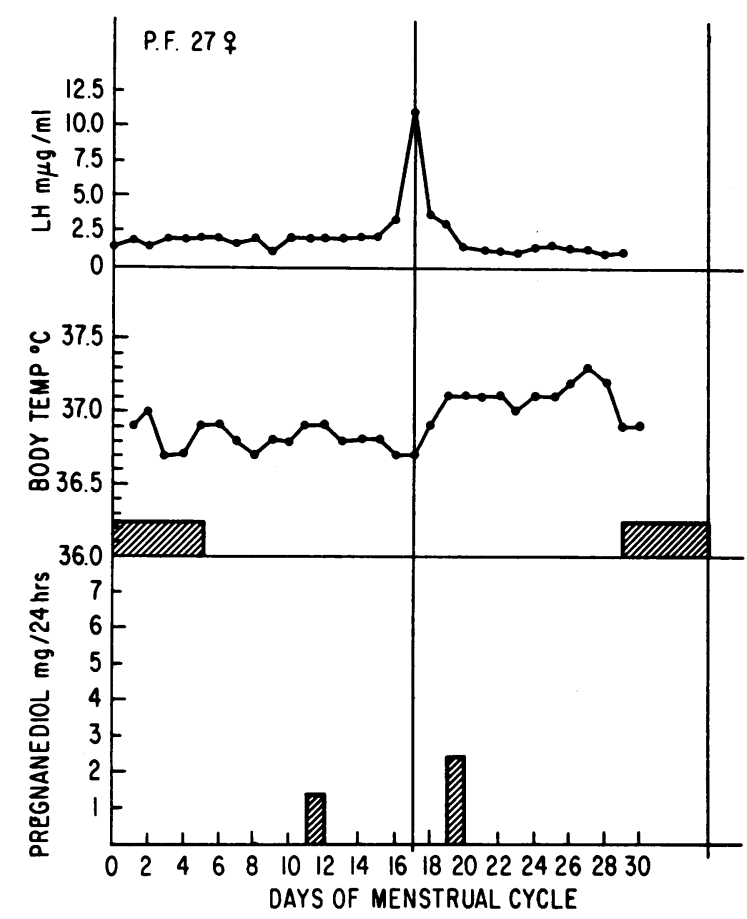

Fig. 4. Plasma LH levels measured daily throughout a menstrual cycle in a 27-year-old woman. Menstrual flow is shown by the shaded bars under the body temperature curve. Note the relative constancy of LH levels except at midcycle. Note also that the mean $\mathrm{LH}$ levels during the follicular phase are higher than during the luteal phase.

fairly constant except at midcycle, where a sharp peak occurred. The mean plasma level of $\mathrm{LH}$ was higher during the follicular phase than during the luteal phase. Also shown are basal body temperatures and pregnanediol excretion. We have followed such changes through a menstrual cycle in 30 women, and the midcycle peak was typically seen at the suspected time of ovulation in 27 . In three women anovulatory cycles were suspected because of a delay of 10 to 20 days in arrival of expected menses, and no midcycle peak was observed. Figure 5 depicts a scattergram of data obtained by measuring plasma $\mathrm{LH}$ daily in ten women throughout the menstrual cycle. A sharp $\mathrm{LH}$ peak ranging from 5.1 to $19.2 \mathrm{~m} \mu \mathrm{g}$ per $\mathrm{ml}$ ( 71.4 to $268.8 \mathrm{mU}$ per $\mathrm{ml}$ ) and occurring as early as day 13 and as late as day 21 was seen during each cycle. Mean plasma $\mathrm{LH}$ levels during the follicular phase averaged $2.0 \pm 0.03$ (SE), whereas during the luteal phase they averaged $1.5 \pm 0.08 \mathrm{~m} \mu \mathrm{g}$ per $\mathrm{ml}$. In all patients examined

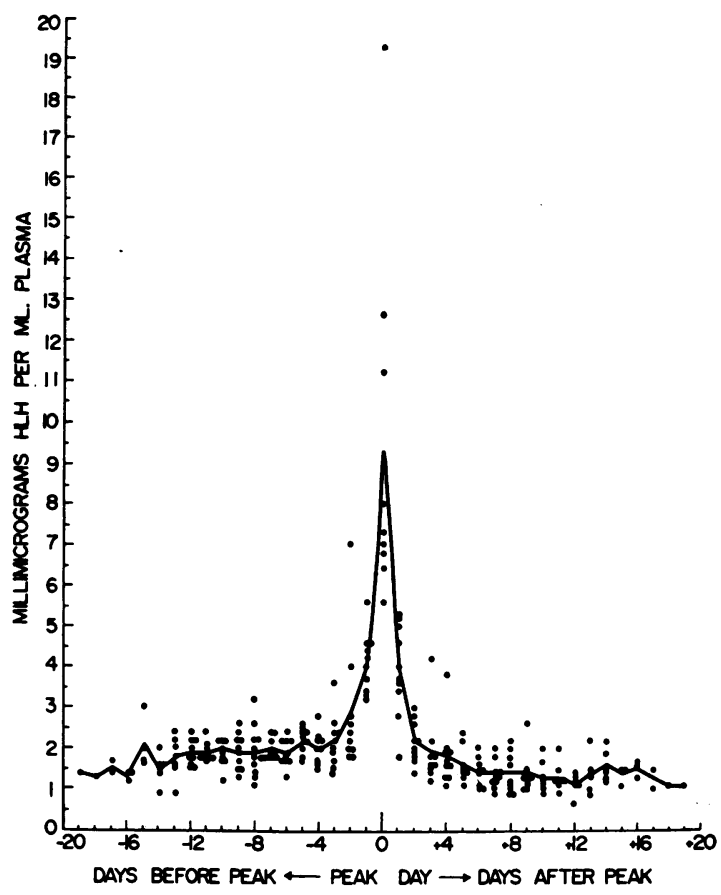

Fig. 5. Scattergram of plasma HLH values meaSURED DAILY IN TEN EUGONADAL WOMEN THROUGHOUT THE MENSTRUAL CYCle. Sample collection was initiated between days 1 and 3 of one menstrual period and terminated on the last day of the following menstrual period. In any one patient, HLH values during the follicular phase always averaged higher than levels during the luteal phase. Data from each patient were plotted by centering all midcycle peaks.

the $\mathrm{LH}$ values obtained during the luteal phase were less than those obtained during the follicular phase. Treatment of 11 of these women with an oral contraceptive agent (Enovid E, $2.5 \mathrm{mg}$ per day) for the next consecutive cycle after the one reported resulted in a complete suppression of this LH peak.

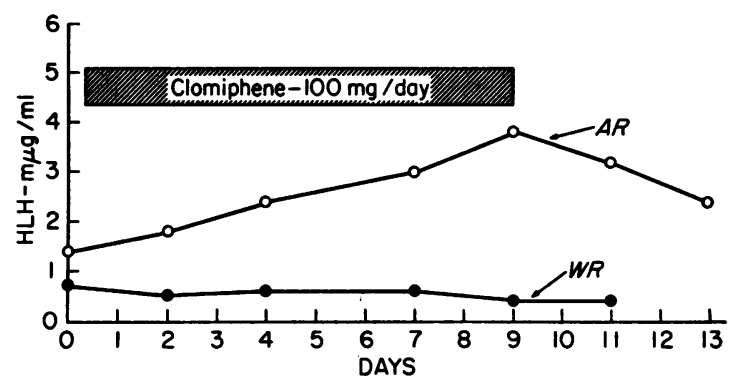

Fig. 6. RESPONSE to CLOMIPHENe tREATMENT OF TWO BROTHERS. W. R. had hypogonadotropic hypogonadism; A. R. was eugonadal. 


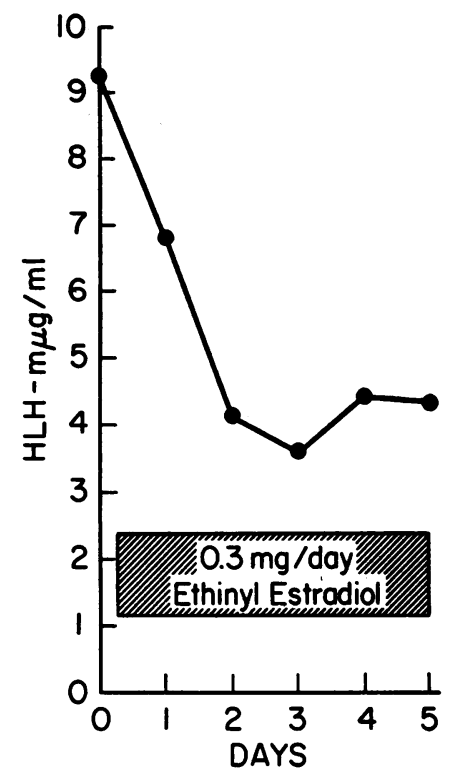

Fig. 7. Plasma LH levels in a postmenopausal WOMAN TREATED With ESTROGEN. Note that LH levels fell by $50 \%$ or more but plateaued at values about twice those seen in eugonadal men and women except at midcycle.

Four normal men have been treated with clomiphene in an attempt to raise plasma $\mathrm{LH}$ levels. In all four normal men plasma $\mathrm{LH}$ rose two to four times after 5 days' treatment. Figure 6 depicts data from two brothers; one suffered from hypogonadotropic hypogonadism, a diagnosis based on physical examination, testicular biopsy, bioassay of ten serial 24-hour urine collections, and ability to increase plasma testosterone levels in response to treatment with human chorionic gonadotropin. His plasma $\mathrm{LH}$ level was $0.8 \mathrm{~m} \mu \mathrm{g}$ per $\mathrm{ml}$ (a low normal value). Treatment for 5 days with $100 \mathrm{mg}$ per day of clomiphene failed to change plasma $\mathrm{LH}$ values. In contrast, his eugonadal brother simultaneously treated with the same medication had a progressive elevation in plasma LH during the treatment period. Further study of these effects of clomiphene on plasma $\mathrm{LH}$ is in progress.

Figure 7 depicts data obtained by treatment of a 58-year-old postmenopausal woman with $0.3 \mathrm{mg}$ of ethinyl estradiol per day for 5 days. Note that initial LH levels were $9.2 \mathrm{~m} \mu \mathrm{g}$ per $\mathrm{ml}$ and that they fell under treatment to levels of $4 \mathrm{~m} \mu \mathrm{g}$ per $\mathrm{ml}$ (still above levels in eugonadal men or women outside the midcycle) and leveled off at this point.

\section{Discussion}

With concentrations of large volumes of urine or plasma and bioassays, a great deal of information has been gained concerning levels of $\mathrm{HLH}$ in human subjects. For example, McArthur and her associates (15) and Apostolakis (16) extracted up to $1,000 \mathrm{ml}$ of blood from postmenopausal women and quantitated HLH by bioassay. More recently Louchart, Truffert, and DeCourt (17) and Keller (18) measured HLH in plasma of normal men. The potency estimates reported by the latter two groups differed by a factor of 40 to 50. Louchart and his colleagues (17) also reported results of bioassay for $\mathrm{HLH}$ in plasma from three normal women in early, middle, and late periods of menstrual cycles. Midcycle values were higher than values obtained at other times during the cycle. Using concentrates of urine, McArthur, Worcester, and Ingersol (19) quantitated HLH throughout the menstrual cycle in normal women. These workers demonstrated a midcycle peak of HLH excretion. Subsequently, these findings were confirmed by Fukushima, Stevens, Gantt, and Vorys (20), Becker and Albert (21), and Rosemberg and Keller (22).

Utilizing immunoassays based on hemagglutination-inhibition and concentrates of urine, several workers have measured HLH during the menstrual cycle. Wide and Gemzell (23), Butt, Cunningham, and Hartree (24), and Sato, Greenblatt, and Mahesh (25) demonstrated midcycle increases in the excretion of immunoreactive material. Our results with radioimmunoassay confirm that the increase in $\mathrm{LH}$ excretion at midcycle is associated with a corresponding peak of $\mathrm{HLH}$ in plasma. This peak of $\mathrm{LH}$ has a value outside the total range of values obtained during other portions of the menstrual cycle. For the first time, it has been shown that plasma levels obtained during the luteal phase are lower than those in the follicular phase. Similarly, confirmation of the elevated levels of HLH found by bioassay of plasma from postmenopausal women has been obtained. Furthermore, assay of eight preparations containing $\mathrm{HLH}$ by biological and radioimmunological means in terms of a common standard has revealed a close correspondence of values. These observations coupled with the similarity of our results to those of Midgley (5) strongly suggest that the radioimmunoassay for HLH is a reliable and spe- 
cific method for quantifying this hormone in plasma. This assay has the obvious advantage of requiring only small volumes of plasma and makes possible repetitive determinations at short time intervals in a single individual. It should come as no surprise that immunoreactive HLH was detectable in plasma from prepubertal children, since $\mathrm{LH}$ activity has been previously demonstrated by bioassay of concentrates of urine from prepubertal children (26).

The presence of gonadotropins in urine and plasma prepubertally suggests that a dynamic pituitary-gonadal interreaction may exist before puberty in man. Such a relationship has been demonstrated in animals. Plasma from prepubertal rats contains $\mathrm{LH}$ that is detectable by its effects on a parabiont hypophysectomized partner (27). When immature rats are joined in parabiosis and one partner is castrated, the other undergoes precocious sexual development (28). This sexual development may be prevented by treatment of the castrate animal with estrogenic steroids in doses that are too small to have any effect on the sex accessories (29). A number of studies are in progress in our laboratory to further elucidate mechanisms of puberty. We have recently observed two prepubertal girls, one age 11 , one age 12 , with castrate levels of plasma $\mathrm{LH}$; both girls have been found to have no gonadal tissue.

The facts that LH is detectable in blood of prepubertal children and that the levels are only slightly lower than in adults challenge our present concepts of mechanisms of puberty. It appears that puberty is not simply caused by onset of gonadotropin secretion, which in turn stimulates gonadal steroid secretion, but by a more complex phenomenon that involves a dynamic pituitarygonadal interrelation before sexual maturation.

The preliminary observations on elevations of plasma LH in response to clomiphene treatment indicated that this may be usable as a test of pituitary LH "reserve" in a fashion similar to the insulin hypoglycemia (20) or pyrogen-induced (21) elevation of growth hormone or to the metopirone release of ACTH (22).

\section{Acknowledgments}

We very gratefully acknowledge the donation of the highly purified human luteinizing hormone preparation by Dr. Anne Stockell Hartree. Without her contribution, this work would not have been possible.

\section{References}

1. Wide, L., P. Roos, and C. Gemzell. Immunological determination of human pituitary hormone ( $\mathrm{LH}$ ). Acta endocr. (Kbh.) 1961, 37, 445.

2. Paul, W. E., and W. D. Odell. Radiation inactivation of the immunological and biological activities of human chorionic gonadotropin. Nature (Lond.) 1964, 203, 979.

3. Odell, W. D., G. T. Ross, and P. L. Rayford. Radioimmunoassay for human luteinizing hormone. Metabolism 1966, 15, 287.

4. Midgley, A. R., Jr., and J. S. Ram. Radioimmunoassay of human chorionic gonadotropin (HCG) and human pituitary luteinizing hormone (LH). Fed. Proc. 1965, 24, 162.

5. Midgley, A. R., Jr. Radioimmunoassay : a method for human chorionic gonadotropin and human luteinizing hormone. Endocrinology 1966, 79, 10.

6. Franchimont, P. Dosage radio-immunologique de l'hormone gonadotrophines folliculo stimulante et luteinisante. Proc. int. Soc. Endocr. January 1966, 303.

7. Butt, W. R., F. J. Cunningham, and A. Hartree. Gonadotropins: preparation and assay of human pituitary FSH and LH. Proc. roy. Soc. Med. 1964, 57, 107.

8. Greenwood, F. C., W. M. Hunter, and J. S. Glover. The preparation of ${ }^{131}$ I-labelled human growth hormone of high specific radioactivity. Biochem. J. 1963, 89, 114.

9. Feinberg, R. Detection of non-precipitating antibodies coexisting with precipitating antibodies using $\mathrm{I}^{131}$ labeled antigen. Fed. Proc. 1954, 13, 493.

10. Morgan, C. R., R. L. Sorenson, and A. Lazarow. Studies of an inhibitor of the two antibody immunoassay system. Diabetes 1964, 13, 1 .

11. Greep, R. O., H. B. VanDyke, and B. F. Chow. Use of anterior lobe of prostate gland in assay of metakentrin. Proc. Soc. exp. Biol. (N. Y.) 1941, 46, 644.

12. Parlow, A. F., P. G. Condliffe, L. E. Reichert, Jr., and A. E. Wilhelmi. Recovery and partial purification of $\mathrm{FSH}$ and $\mathrm{LH}$ during the purification of TSH from human pituitary glands. Endocrinology 1965, 76, 27.

13. Reichert, L. Personal communication.

14. Tullner, W. W., and R. Hertz. Chorionic gonadotropin levels in the rhesus monkey during early pregnancy. Endocrinology 1966, 78, 204.

15. McArthur, J. W., H. N. Antoniades, L. H. Larson, R. B. Pennell, S. M. Ingersoll, and H. Ulfelder. Follicle-stimulating hormone and luteinizing hormone content of pooled human menopausal plasma and of subfractions prepared by Cohn methods 6 and 9. J. clin. Endocr. 1964, 24, 425. 
16. Apostolakis, M. Detection and estimation of pituitary gonadotrophins in human plasma. J. Endocr. 1960, 19, 377.

17. Louchart, J., J. Truffert, and J. DeCourt. Dosage de l'hormone luteinisante dans le plasma humain. Resultats chez les sujets normaux des deux sexes. Acta endocr. (Kbh.) 1965, 49, 293.

18. Keller, P. J. Studies on pituitary gonadotropins in human plasma. Acta endocr. (Kbh.) 1966, 52, 348.

19. McArthur, J. W., J. Worcester, and F. M. Ingersol. The urinary excretion of interstitial-cell and follicle-stimulating hormone activity during the normal menstrual cycle. J. clin. Endocr. 1958, 18, 1186.

20. Fukushima, M., V. C. Stevens, C. L. Gantt, and N. Vorys. Urinary FSH and $\mathrm{LH}$ excretion during the normal menstrual cycle. J. clin. Endocr. 1964, 24, 205.

21. Becker, K. L., and A. Albert. Urinary excretion of follicle-stimulating and luteinizing hormones. J. clin. Endocr. 1965, 25, 962.

22. Rosemberg, E., and P. J. Keller. Studies on the urinary excretion of follicle-stimulating and lu- teinizing hormone activity during the menstrual cycle. J. clin. Endocr. 1965, 25, 1262.

23. Wide, L., and C. Gemzell. Immunological determination of pituitary luteinizing hormone in the urine of fertile and post-menopausal women and adult men. Acta endocr. (Kbh.) 1962, 39, 539.

24. Butt, W. R., F. J. Cunningham, and A. S. Hartree. Preparation and assay of human pituitary $\mathrm{FSH}$ and LH. Proc. roy. Soc. Med. 1964, 57, 107.

25. Sato, T., R. B. Greenblatt, and V. B. Mahesh. Levels of luteinizing hormone during the menstrual cycle determined by immunologic technics. Fertil. and Steril. 1965, 16, 223.

26. Fitschen, W., and B. E. Clayton. Urinary excretion of gonadotropins with particular reference to children. Arch. Dis. Childh. 1965, 40, 16.

27. Johnson, D. C. The use of non-castrate parabiotic rats for evaluation of plasma gonadotropin. Acta endocr. (Kbh.) 1966, 51, 269.

28. Kallas, H. Preburte prococe par parbiose. C. R. Soc. Biol. (Paris) 1929, 100, 979.

29. Byrnes, W. W., and R. K. Meyer. The inhibition of gonadotrophic hormone secretion by physiological doses of estrogen. Endocrinology 1951, 48, 133. 